\title{
Anti-swing device modeling of ship-mounted crane
}

\author{
ZHANG Tong", a , HAN Guang-dong ${ }^{1}$, CHEN Hai-quan", ZHANG Jin-nan", \\ WANG Sheng-hai ${ }^{1}$ \\ ${ }^{1}$ College of Marine Engineering, Dalian Maritime University, Dalian 116026, Liaoning, China \\ a18842602951@163.com
}

Keywords: ship-mounted crane; Anti-swing device; kinematics model; Mat lab/Simulink software Abstract:To suppress the swing of the payload, a kind of hanging plate anti-swing device was designed, which reduced the length of the lifting rope and the swing of payload by using the constant tension hanging plate. The kinematic equations of the payload were established under the condition of whether hanging plate was provided, and the dynamic was carried out in Mat lab/Simulink environment. The swing of the payload under different rolling angles was analyzed in a comparative manner. The results showed that the in-plane angle reduced $60 \%$ and out -plane angle reduced $55 \%$ of the payload in the case of the hanging plate.

\section{Introduction}

The ship-mounted crane is a kind of rotary hydraulic crane fixed on the deck, mainly used for cargo transfer between ship and ship, ship and port, in addition, the ship-mounted crane also plays a vital role in the materials supply of military ship. However, the efficiency and safety of ship crane are affected by the swing of payload due to wind, wave, current external environment and their own manipulation in the process of ship crane operations. Therefore, it is very important for the safety and efficiency of the ship crane operation to develop the dynamic model and dynamic analysis of the marine crane payload system [1]. In the study of the dynamics of the crane system, there are two commonly used dynamic model. One is to simplify the direct effect of the hull on payload to the harmonic excitation of the rope hanging point on lifting arm. In fact, the payload is simplified a spatial swinging in this model [2-4]. The results showed that even in the planar motion of hanging point, the payload can also make swing space under certain conditions, or even chaotic motion [5-6]. The second model is the ship motion and the swing of payload coupling analysis and develop the multi-body dynamics model [7-9]. SCHELLIN T E put forward that hull and payload system can be divided into two parts to consider [10], transfer the motion of the hull as an incentive of base, then pass the incentive to payload.

\section{Kinematic model of the payload}

In fact, the crane itself exists mutual coupling of rigid body and elastomer. In addition, the crane motion is also subject to the interaction of the hull and the wind, wave, flow, inertial loads and other external loads, with strong nonlinear characteristics. In paper the ship is looked as an incentive platform, to carry on the roll in order to facilitate the research the following assumptions are made. The payload could be looked as particle and the quality of rope is negligible compared to the payload the rope without elastic deformation the lifting arm of ship crane as rigid body without elastic deformation ship motion in regular waves.

According to the above assumptions the spatial motion model of the crane payload system was 
developed, as shown in Fig. 1.

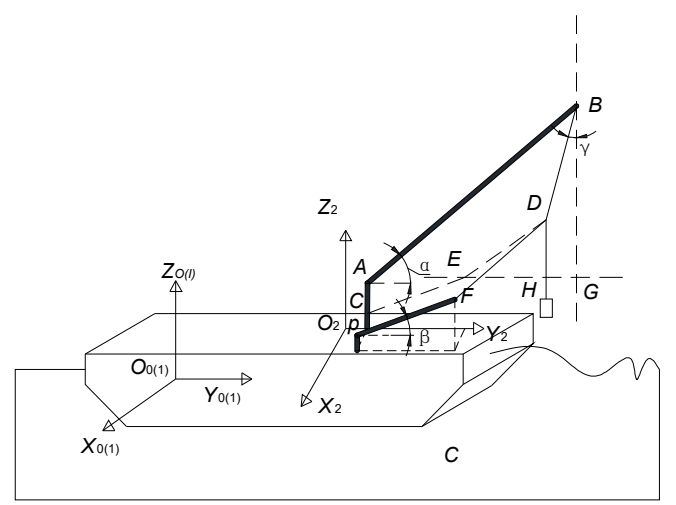

Figure 1 The model of the ship crane payload system

Which each frame of reference coordinate system is defined as follows $\left(O_{0}-X_{0} Y_{0} Z_{0}\right)$ as the inertial coordinate system, $\left(O_{1}-X_{1} Y_{1} Z_{1}\right)$ for positioning in the hull on the hull system, the initial state, the inertia coordinate system and earth coordinate system is $\left(O_{1}-X_{1} Y_{1} Z_{1}\right)$ and $\left(O_{0}-X_{0} Y_{0} Z_{0}\right)$ overlap, the ship six degree of freedom coordinate curve are motivated by the wave motion, $\left(O_{2}-X_{2} Y_{2} Z_{2}\right)$ for positioning on the base coordinate system origin $\mathrm{O}_{2}$ for crane base and the intersection of hull, coiling $Z_{2}$ axis rotation with the angle theta $X_{2}-Y_{2}$ plate, the point $p$ is located in the base coordinate system $\left(\mathrm{O}_{2}-\mathrm{X}_{2} Y_{2} \mathrm{Z}_{2}\right)$ with $\mathrm{O}_{2}$ point in overlap, $\gamma$ is the initial Angle with the $Z$ axis after the wire join into stage Marine crane arm lifting point motion is mainly composed of the rotation of rotary disk, the luffing of lifting arm and the motion of the hull. Through coordinate transformation, the coordinate system on the base of the crane could be represented in the hull coordinate system, transformation relation as follow.

$$
u_{p}=\mathrm{T}_{O_{2}}^{O_{1}} p^{o_{2}} \text {. }
$$

In the formula the corresponding reference coordinates after coordinate transformation was represented with superscript and subscript, $u_{p}=\left[\begin{array}{lll}x_{p} & y_{p} z_{p} & 1\end{array}\right]^{\mathrm{T}}$ is the position coordinate which is the base of the origin of $O_{2}$ in the hull coordinates system $\left(O_{1}-X_{1} Y_{1} Z_{1}\right)$, and $p^{O 2}=\left[\begin{array}{llll}0 & 0 & 0 & 1\end{array}\right]^{\mathrm{T}}$ is the position coordinate which is base original point in base coordinates system, $\mathrm{T}$ as the coordinate transformation matrix between the base coordinate system $\left(O_{2}-X_{2} Y_{2} Z_{2}\right)$ and the hull coordinate system $\left(O_{1}-X_{1} Y_{1} Z_{1}\right)$.

$$
T_{O_{2}}^{O_{1}}=\left[\begin{array}{cccc}
\cos \alpha & -\sin \alpha & 0 & x_{o_{2}} \\
\sin \alpha & \cos \alpha & 0 & y_{o_{2}} \\
0 & 0 & 1 & z_{o_{2}} \\
0 & 0 & 0 & 1
\end{array}\right] .
$$

Where $x_{o 2}, y_{o 2}, z_{o 2}$ are the coordinates of the point $O_{2}$ in the hull coordinate system $\left(O_{1}-X_{1} Y_{1} Z_{1}\right)$.

Due to the motion of the ship, caused the lifting arm of motion of parallel attitude, but since the hanging point of lifting arm and cargo are connected by wire ropes, only three displacements can be transmitted to the payload to cause the swing of the payload, but the attitude movement is not affected, so only need to derive the translational displacements of crane base, the expression as follow.

$$
u_{o_{2}}=u_{p}+H u_{o_{1}} .
$$




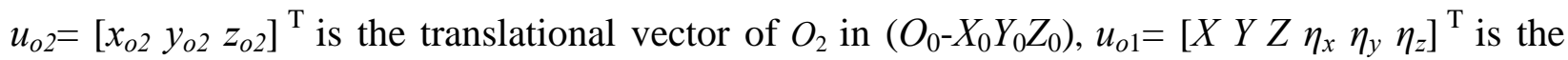
motion vector of the hull, assuming that the ship motion is in a regular wave, considering only the ship rolling and pitching, it can be assumed that the motion vector of the ship as follow.

$$
u_{o_{1}}=\left[\begin{array}{llllll}
0 & 0 & 0 & \eta_{x} & \eta_{y} & 0
\end{array}\right]^{\mathrm{T}} \text {. }
$$

Under the condition of without considering the rotation of the crane, the crane as a whole as a rigid body, $\alpha=0$, so the change of the coordinates of crane basis points can be represented by matrix $\mathrm{H}$ as follow.

$$
H=\left[\begin{array}{cccccc}
1 & 0 & 0 & 0 & z_{p} & -y_{p} \\
0 & 1 & 0 & -z_{p} & 0 & x_{p} \\
0 & 0 & 1 & y_{p} & -x_{p} & 0
\end{array}\right] .
$$

According Eq.1-Eq.5

$$
u_{b}=\left(1.5 * \eta_{y},-1.5 * \eta_{y}+3.5,3.5 * \eta_{y}+1.5\right) \text {. }
$$

The coordinates of point B, E, F can be derived by using the coordinates of $u_{b}$ as follows.

$$
\left\{\begin{array}{l}
B\left(x_{b}, y_{b}, z_{b}\right)=\left(1.5 * \eta_{y},-1.5 * \eta_{x}+4.56,3.5 * \eta_{y}+2.76\right) \\
E\left(x_{e}, y_{e}, z_{e}\right)=\left(-1.5 * \eta_{y}-0.2,-1.5 * \eta_{x}+3.93,3.5 * \eta_{x}+1.85\right) \\
F\left(x_{f}, y_{f}, z_{f}\right)=\left(1.5 * \eta_{y}+0.2,-1.5 * \eta_{x}+3.93,3.5 * \eta_{y}+1.85\right)
\end{array} .\right.
$$

By using the method of Descartes, the force analysis was carried out.

(1) Statics analysis of the hanging plate

The statics analysis in $X, Y, Z$ direction is

$$
\begin{aligned}
& F_{1} *\left(\left(x_{f}-x_{d}\right) / l_{d f}+\left(x_{e}-x_{d}\right) / l_{d e}\right)+F_{2} *\left(\left(x_{h}-x_{d}\right) / l_{d h}+\left(x_{b}-x_{d}\right) / l_{b d}\right)=0 . \\
& F_{1} *\left(\left(y_{f}-y_{d}\right) / l_{d f}+\left(y_{e}-y_{d}\right) / l_{d e}\right)+F_{2} *\left(\left(y_{h}-y_{d}\right) / l_{d h}+\left(y_{b}-y_{d}\right) / l_{b d}\right)=0 . \\
& F_{1} *\left(\left(z_{f}-z_{d}\right) / l_{d f}+\left(z_{e}-z_{d}\right) / l_{d e}\right)+F_{2} *\left(\left(z_{h}-z_{d}\right) / l_{d h}+\left(z_{b}-z_{d}\right) / l_{b d}\right)=0
\end{aligned} .
$$

(2) Kinematics analysis of the payload (With the hanging plate)

The statics analysis in $X, Y, Z$ direction is

$$
\begin{aligned}
& m \ddot{x_{h}}=F_{2} *\left(x_{d}-x_{h}\right) / l_{d h} . \\
& m \ddot{y_{h}}=F_{2} *\left(y_{d}-y_{h}\right) / l_{d h} . \\
& m \ddot{z}=F_{2} *\left(z_{d}-z_{h}\right) / l_{d h}-m g .
\end{aligned}
$$

(3) Kinematics analysis of the payload (Without the hanging plate)

The statics analysis in $X, Y, Z$ direction is

$$
m \ddot{x_{h}}=F_{2} *\left(x_{b}-x_{h}\right) / l_{b h} \text {. }
$$




$$
\begin{aligned}
& m \ddot{y}_{h}=F_{2} *\left(y_{b}-y_{h}\right) / l_{b h} . \\
& m \ddot{z}_{h}=F_{2} *\left(z_{b}-z_{h}\right) / l_{b h}-m g .
\end{aligned}
$$

\section{The kinematic simulation analysis of payload system}

According to the kinematics equations of the payload above, the simulation analysis of the motion of the payload was carried out under the condition of whether hanging plate is provided in where respectively the rolling angles are $6^{\circ}, 11^{\circ}, 16^{\circ}$.

(1) The swing of the payload when the rolling angles is $6^{\circ}$
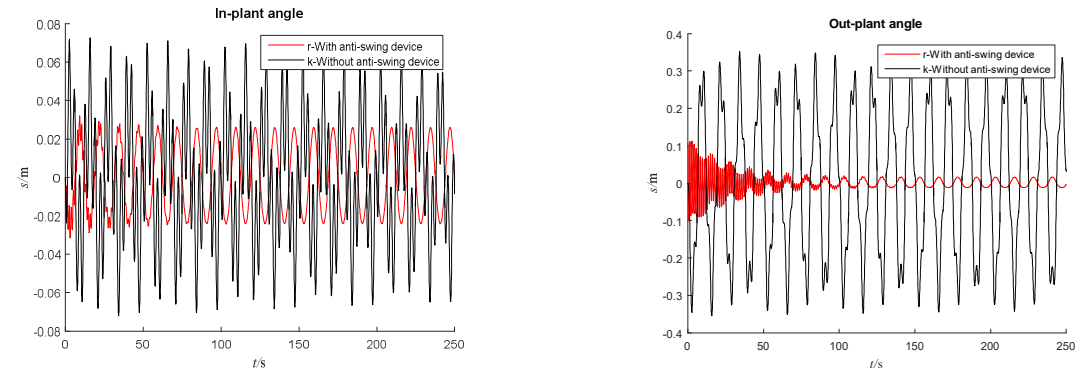

Figure 2 The swing curve of the payload when the rolling angles is $6^{\circ}$

From Fig. 2 can be concluded that the ship rolling angle is $6^{\circ}$ under the condition of no anti-swing device, the maximum in-plane swing of the payload is $0.074 \mathrm{~m}$, the maximum out-plane swing of the payload is $0.35 \mathrm{~m}$. Under the condition of anti-swing device, the maximum in-plane swing of the payload is $0.031 \mathrm{~m}$, the range of anti-swing is $58.1 \%$, the maximum out-plane swing of the payload is $0.13 \mathrm{~m}$, the range of anti-swing is $62.9 \%$.

(2) The swing of the payload when the rolling angles is $11^{\circ}$
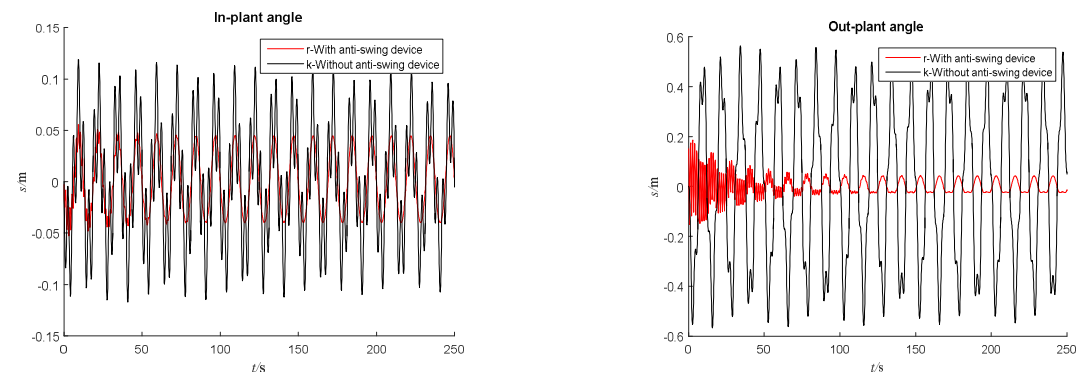

Figure 3The swing curve of the payload when the rolling angles is $11^{\circ}$

From Fig. 3 can be concluded that the ship rolling angle is $11^{\circ}$ under the condition of no anti-swing device, the maximum in-plane swing of the payload is $0.129 \mathrm{~m}$, the maximum out-plane swing of the payload is $0.57 \mathrm{~m}$. Under the condition of anti-swing device, the maximum in-plane swing of the payload is $0.058 \mathrm{~m}$, the range of anti-swing is $55.03 \%$, the maximum out-plane swing of the payload is $0.20 \mathrm{~m}$, the range of anti-swing is $64.9 \%$.

(3) The swing of the payload when the rolling angles is $16^{\circ}$ 

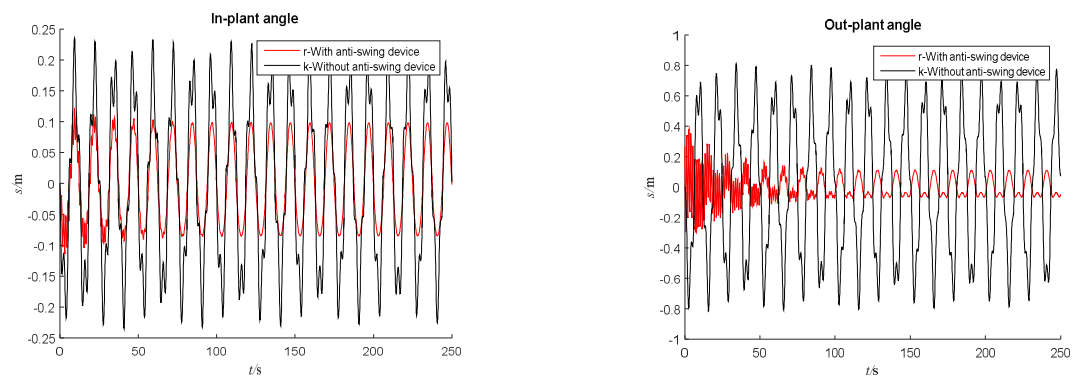

Figure 4 The swing curve of the payload when the rolling angles is $16^{\circ}$

From Figure 4 can be concluded that the ship rolling angle is $16^{\circ}$ under the condition of no anti-swing device, the maximum in-plane swing of the payload is $0.24 \mathrm{~m}$, the maximum out-plane swing of the payload is $0.81 \mathrm{~m}$. Under the condition of anti-swing device, the maximum in-plane swing of the payload is $0.113 \mathrm{~m}$, the range of anti-swing is $52.9 \%$, the maximum out-plane swing of the payload is $0.39 \mathrm{~m}$, the range of anti-swing is $51.9 \%$.

\section{Conclusions}

The kinematic model of the payload is established and the simulation analysis of the motion of the payload is obtained by using Simulink when the rolling angles are $6^{\circ}, 11^{\circ}, 16^{\circ}$. According to the results, the hanging plate anti-swing device can reduce the swing amplitude of the payload by 55\%. The effectiveness of the hanging plate anti-swing device is verified, it has a certain significance to improve the safety and efficiency of ship crane.

\section{Acknowledgements}

This work was financially supported by the Fundamental research funds for the Central Universities (3132016356, 3132016345, 3132016344).

\section{References}

[1] WANG Xuelin, YOU Xinyi, HU Yujin. Cargo pendulation analysis of moored crane ship under regular waves[J]. China Mechanical Engineering, 2010, 9: 1077-1082.

[2] HENRY R J, MASOUD Z N, NAYFEH A H, et al. Cargo pendulation reduction of ship-mounted cranes via boom-luff angle actuation[J]. Journal of Vibration and Control, 2001, 7(8): 1253-1264.

[3] CHIN C, NAYFEH A H, ABDEL-RAHMAN E. Nonlinear dynamics of a boom crane[J]. Journal of Vibration and Control, 2001, 7(2): 199-220.

[4] CHIN C M, NAYFEH A H. Dynamics and control of ship-mounted cranes[J]. Journal of Vibration and Control, 2001, 7(6): 891-904.

[5] ELLERMANN K, KREUZER E, MARKIEWICZ M. Nonlinear dynamics in the motion of a floating cranes[J]. Multibody System Dynamics, 2003, 9(4): 377-387.

[6] PARK KP, CHA JR, LEE KY, et al. Modeling of Multi-Boom Floating Crane for Lifting Analysis of Offshore Wind Turbine[J]. Transactions of the Korean Society of Mechanical 
Engineers A, 2011, 35: 115-120.

[7] MILES J W, Stability of force oscillations of a spherical pendulum[J]. Journal of the Acoustical Society of America, 1962, 20(1):21-32.

[8] MILES J W, Resonant motion of a spherical pendulum[J]. Physica D Nonlinear Phenomena, 1984, 11(3): 309-323.

[9] PATEL M, BROWN D, WITZ J A. Operability analysis for a manual crane vessel[J]. Transaction of the Royal Institute of Naval Architects, 1987, 129: 103-113.

[10] SCHELLIN T E, JIANG T, SHARMA S D. Crane ship response to wave groups. Journal of Offshore Mechanics and Arctic Engineering, 1991,113:211-218. 